\title{
SYSTEM ISSUES AND REQUIREMENTS OF HOTEL MARKETING MANAGEMENT
}

\author{
Jelena Đaković ${ }^{1}$ \\ Angelina Njeguš², \\ Nikola Milović ${ }^{1}$
}

\author{
'Square Nine Hotel, \\ Studentski trg 9, Belgrade, Serbia \\ ${ }^{2}$ Singidunum University, \\ 32 Danijelova Street, Belgrade, Serbia
}

\begin{abstract}
:
In this paper, the main marketing management processes, their changes under the influence of Web 3.0 services and user behavior, information technologies that are currently used in hotels, and the influence of big data analytics systems, are discussed. Many hotels today are struggling with their data. Therefore, the authors want to gain better understanding of the problems and issues the hotels are facing, as well as to gather their requirements for future big data analytic systems. Since problems are arising with the size of the hotel, this paper shall analyze only small-sized hotels. Despite the advantages that big data analytic applications bring, they still did not find wider application in hotels. In order to analyze issues related to the implementation of big data analytic system within hotels, the small-sized hotel located in Belgrade is analysed in this study.
\end{abstract}

Key words:

marketing, social media, big data, mobile technologies, system requirements.

\section{INTRODUCTION}

Since marketing is defined as the process that creates value for customers through stronger customer relationships (Kotler et al, 2013), the hotel marketing managers are focused on:

- how to improve customer satisfaction,

- how to personalize marketing campaigns and services,

- how to offer the right room at the right moment and at the right rate,

- how to expand on to other markets and reach prospective customers.

Traditional information systems that are installed in hotel environment are not sufficient to cope with these requirements. Today, customers are active on the Internet, using different internet services, such as search engines, social media, mobile applications and games. Thus, massive amounts of data are generated, with the hotels not being aware of that.

Guest database within Customer Relationship Management (CRM) system does not tell much about the guest, except for her/his movement during the stay at the hotel. There is a need to enrich this data with the guest activity and behavior on the Internet. However, these data are generated rapidly, and traditional systems are not meant for processing huge amounts of data in real time (so called big data). Therefore, new technologies and systems are developed in order to collect, process and analyze big data. 
Numerous hotels are nowadays struggling with their data, which is why this paper shall attempt to provide insight into the problems and issues the hotels are facing, as well as to gather their requirements for future big data analytic systems. Since the problems are arising with the size of the hotel, only small-sized hotels (5-50 rooms) shall be covered in this analysis.

The paper comprises two main parts. The first part discusses the main marketing management processes, their changes under the influence of Web 3.0 services and user behavior, information technologies that are used within hotels, and the influence of big data analytics systems. The second part examines the current situation of IT and applications that marketing managers use in their everyday job based on the case study of the hotel Square Nine in Belgrade. The current issues of marketing managers are also discussed herein.

\section{LITERATURE REVIEW AND THEORETICAL BACKGROUND}

The marketing management process has changed under the influence of the emerging technologies and changes in consumer behavior (Figure 1). From management perspective it turned to social with an emphasis on understanding consumers and competing behaviors through research, segmentation, $7 \mathrm{P}$ and $7 \mathrm{C}$ marketing mix implementation, exchange of benefits, and analytics with purpose of constant learning and improvement (Burchell et al, 2013). Inevitably, development of information and internet technologies have accelerated this process, but also provide support and assistance in carrying out these activities (Law et al, 2009). Today, without adequate tool/system or IT strategy in general, marketing managers may put hotel in at a competitive disadvantage. On the other hand, consumers are increasingly empowered and smart, and come with a number of expectations (Table 1), boosted by mobile, social, cloud, big data and other technologies.

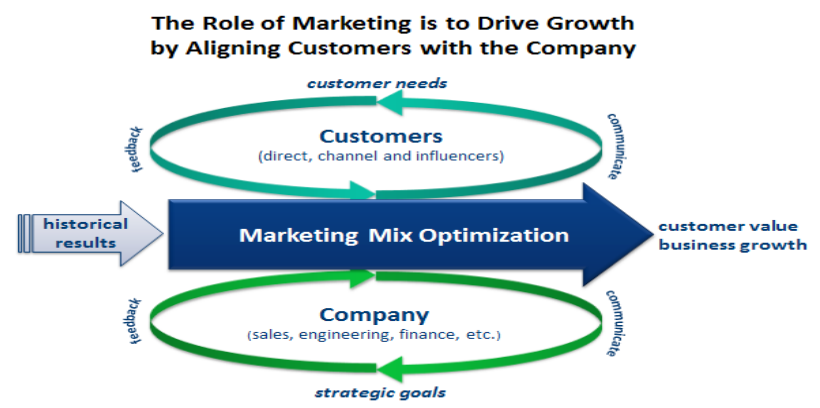

$\overline{\text { Figure 1. Marketing management process (York, 2015) }}$
The most hotels today are equipped with traditional Enterprise Resource Planning (ERP) systems, so called Property Management Systems (PMSs), such as Fidelio, Protel, RMS and other. Much effort is done on integration of PMSs with other systems, such as: Customer Relationship Management (CRM), Computer Reservation Systems (CRSs), Revenue Management Systems (RMS), Supply chain Management Systems and other. Majority of these systems are nowadays available on the cloud using mobile platforms. However, all these systems are dealing more with management perspective instead of social. As said above, the social aspect includes all user generated content (UGC) available on social media. The issue that arises here is that traditional systems and technologies are not meant for processing big data that are generated every second in different data formats (Xiang et al, 2014).

\begin{tabular}{lc}
\hline \multicolumn{1}{c}{ Customer expectations } & $\%$ of respondents \\
\hline Access to Services Faster than ever & $55 \%$ \\
\hline $24 / 7$ Access and connectivity & $53 \%$ \\
\hline Access to More Platforms & $50 \%$ \\
\hline Personalized Experience & $47 \%$ \\
\hline Greater transparency in interactions & $38 \%$ \\
\hline $\begin{array}{l}\text { Easier collaboration and sharing } \\
\text { with other customers }\end{array}$ & $25 \%$ \\
\hline
\end{tabular}

Table 1. Consumer expectations

(Source: Institute for the future, 2015)

Big data can be defined as a new generation of technologies, architectures and analytic systems, that are designed to economically and in real time capture, extract, store, process, discover, and analyze very large volumes of a wide variety of data (Wren et al, 2014) (Njeguš et $a l, 2015)$. Marketing managers can directly benefit from big data analytic systems in a way to (Salkowitz, 2014):

- better track performance of marketing investments

- personalize brand experiences

- improve message targeting

- deliver personalized products/services with personalized pricing

- anticipate new opportunities through predictive analysis

- attract and retain individual customer at the lowest cost

- manage ongoing relationship at optimum levels of profitability. 
Big data analytic systems can involve not only social media content, but also other data generated by sensors, mobile phones, and from other digital channels, that are turned into digital signals (Figure 2). By analyzing these signals, we can learn about customers, as follows (Hendrix, 2013):

- Searched data - key words or sentences, entered into search engines, by the customer, can tell about his/her interest, wishes, intentions.

- Location data - mobile phones generate location data, and these data can tell where consumer is, how often, who else is there, etc.

- Purchase data - these information tell who buys and almost what is bought.

- Social data - identity data, and the way user interact with others.

- Interest data - what user is interested in, like tweets, checkins, etc.

- Content data - what user reads/watches/consumes when, what, etc.

Big data analytic systems represent these data in three different perspectives (Figure 2): (a) historical analysis to better understand what happened in the past (b) real time monitoring of big data - to evaluate what happens at present and (c) predictive analysis - predict the behavior of instances in the future.
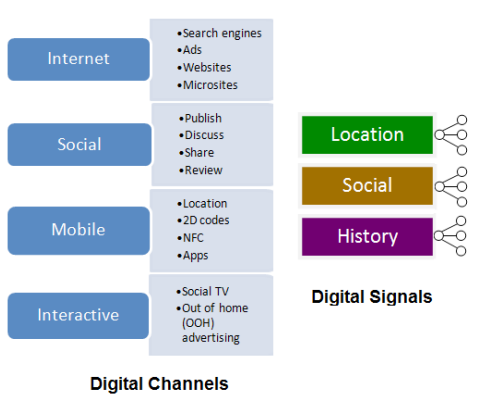

Digital Channels

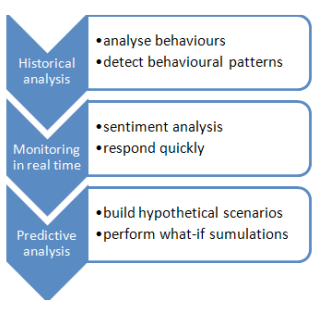

Big Data Analytics
Figure 2. Big data analytics on different dimensions

(Baquero et al, 2014) (Hendrix, 2013)

According to Hendrix (2013), 4P's can be switched to PEER strategies:

- Personalize - analyzing customer data we should learn and adapt

- Enable - Remove frictions

- Enhance - Surprise/delight customer

- Reward - Reinforce customer

\section{MARKETING MANAGEMENT ISSUES AND SYSTEM REQUIREMENTS: SQUARE NINE HOTEL BELGRADE}

Despite the advantages that big data analytic applications bring, they still have not found wider application in hotels. In order to analyze issues implementing big data analytic system within hotels, only small-sized hotels are covered in this study.

Square Nine hotel is a five-star hotel in Belgrade. It has 45 rooms and belongs to the category of small sized hotels. It has excellent reviews on social network websites. In a short period of time, hotel management have changed from looking at marketing as a function of sales, to having full-fledged marketing teams with individual specialists for segments such as PR and Social Media. However, it is still predominately one-person job, even with the role of marketing manager changing and growing over time.

The duties of a hotel marketing manager are simply defined as the overall presentation of the hotel and the building of the brand positioning and image of the hotel among the local and foreign public. This is achieved through printed materials, in hotel communication through all available channels, traditional advertising campaigns, positioning of the hotel on Google and on-line sales and distribution channels, on line advertising, social media, trade fairs, specialized events inside and outside of the hotel and sponsorships. The position also requires budgeting for all of these activities, scanning activities of the competition, tracing the efficiency of the activities that are done for the promotion of the hotel and reporting. Finally, the position entails the creation of special packages, designed to bundle hotel products into single, more attractive packages, with an enticing price. These should be designed with a good grasp of the market, target audience, consumer needs, and hotel vs. competition pricing policies in mind. Ideally, the marketing manager should help the sales department draw interested customers towards the hotel, and open a communication process with them, and also position the hotel as great value for the requested price in all segments and aspects.

With the changing world and the growing importance of on-line communication, and especially social media, as well as the growing social aspect in traditional positioning and sales channels for hotels, such as booking. com or Trip Advisor, the role of the marketing manager has started to entail an array of different duties. These duties are to: create an interesting and engaging flow of social media content, keep a line of open two-way communication with follower public, answer all comments 
and questions in any channel and form that they are delivered in, make sure that the image of the hotel that is created on third party channels (such as Trip Advisor and Booking.com) is adequate to the image that the hotel wished to portray itself. All of these channels have become the most important and effective tool in image and brand building, as well as more of a sales channel than any of the traditional ones are, and they are rapidly growing in importance. The content creation is one of the largest aspects of this work, as the content should be interesting and relevant to the target audience, as well as deeply connected with the hotels daily life and activities.

Many brands and companies today hire the professional, so called community manager (Živković et al, 2015), or professional teams for social media management and content management, that are solely in charge of providing a constant stream of content, or simply to publish multimedia information. This can at times become overwhelming, since the basic channels that pretty much all hotels today communicate with guests, are through website, search engines, social media and online travel agencies (OTA). As community managers do their jobs manually, the solution would be in using specialized big data analytic systems.

Information technologies that are implemented in the hotel Square Nine are:

- Hardware (Figure 3)

- Software:

- Fidelio

- Micros

- Materials Control

- Accounting system

- Network: Free Wife, throughout the hotel, 30 Mbits upload/30 Mbits download

- Pay TV

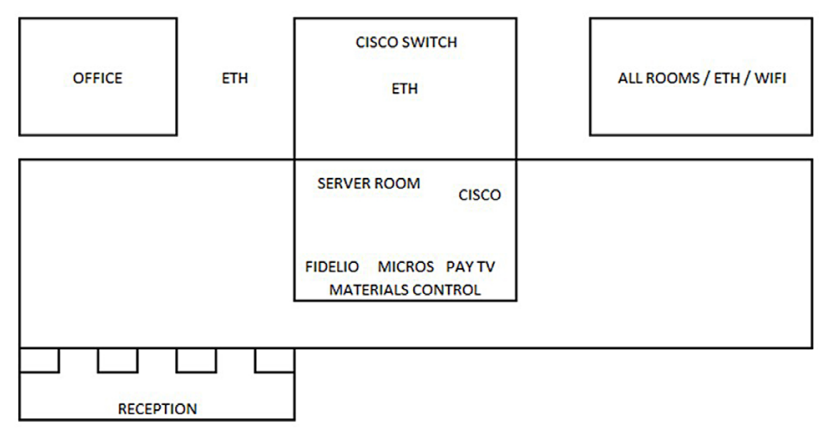

Figure 3. IT distribution within hotel sectors
Internet technologies that are used at Square Nine, are:

- The hotel web site (www.squarenine.rs)

- The hotel blog (www.square-nine.rs)

- The group web site (www.lhw.com)

- Social media:

- Facebook (www.facebook.com/squarenine),

- Instagram (www.instagram.com/squareninehotel),

- Twitter (twitter.com/squareninehotel),

- LinkedIn (www.linkedin.com/company/ square-nine),

- Youtube (channel/UCNwsWH_ivdDlarP8HEJ0uEg)

- Google positioning: Google maps, Google +, Google street view

- Google metrics: Google analitics

- Survey monkey

- Dropbox

- WeTransfer

- Hotel Mobile App

- Sales and distribution channels: Booking.com, Expedia, HotelBeds, etc .

- TripAdvisor as a special and unique channel.

The hotel receives constant feedback and information through each of these channels, from its existing guests, potential guests, fans, competition and others. Additional feedback is received through online surveys sent to each gust after departure, and information about guests is collected during their stay, and added to their profiles in the hotel software (in our case Fidelio). Each of the channels provides its own statistic and/or panel for communication, but there is no single panel through which all of these inputs could be connected, reviewed, tracked, or managed. Some current issues are:

- Fidelio is inflexible, it is very difficult to get certain data or types of reports from it.

- Fidelio cannot be, or can very hardly be connected and integrated with other software.

- Each of the technologies used collects its own set of data, but there is no way to connect all of it.

- Many aspects of operation are done manually, although a better system would be able to do it more efficiently (ordering of supplies, store keeping ...)

The main system requirements for the future applications are collecting and connecting guest information from all available sources (internal and external), and offering an easy way to access it, analyze and communicate. 


\section{CONCLUSION}

Considering that one of the key trend in hotel industry today is the new customer segment, so called generation $\mathrm{Z}$ (also iGen or Millennials) - the fastest growing segment in the hotel industry - the hotel will need to quickly adapt and prepare tits environment for this generation. By 2025, it is expected that Millennials will represent more than $50 \%$ of all travelers. Since technology is essential for this demographic group, hotels should pay special attention to empathy and customer connection through social media using personalized and technology powered hotel processes and services. For those self-sufficient travelers, hotels need to offer mobile check-in, geo-location software, personalized and other services. In this paper, we wanted to analyze the current situation in hotel marketing management, their issues and future information system requirements. The goal was to analyze the current trends in marketing management, and examine the level of their implementation in hotels. For that purpose, the smallsized hotel located in Belgrade was analyzed.

\section{REFERENCES}

Baquero, A.V., Ralacios, R.C., Molloy, O. (2014) Towards a process to guide Big Data based Decision Support Systems for Business Processes. Procedia Technology. Vol. 16, pp: 11-21.

Burchell, K., Rettie, R., Patel, K. (2013) Marketing social norms: Social marketing and the social norm approach. Journal of Consumer Behaviour. Vol. 12, pp: 1-9.

Hendrix, P. (2013) How Big Data is Reshaping Marketing. Immr. Available at: http://www.immr.org/howbig-data-is-reshaping-marketing.pdf (accessed: 22.02.2016).

Institute for the future (2015) The information generation: Transforming the future, today. Outlook Re- port. EMC2. Available at: https://www.emc.com/ information-generation/resources/IFTF_Outlook_ Report.pdf (accessed: 20.02.2016).

Kotler, P.T., Bowen, J.T., Makens, J. (2013) Marketing for Hospitality and Tourism. Sixth edition. Pearson Education.

Law, R., Leung, R., and Buhalis, D. (2009) Information Technology Applications in Hospitality and Tourism: A Review of Publications from 2005 to 2007. Journal of Travel \& Tourism Marketing, 26(5), pp.599-562.

Njegus, A., Jovanović, V., Veinović, M. (2015) Challenges and Opportunities of Big Data Analytics in the Hospitality Industry. Proceedings of X International scientific conference. Zlatibor, 29-31.10.2015. Vol. 3, Iss. 1, pp: 1-18.

Salkowitz, R. (2014) From Big Data to Smart Data: Using data to drive personalized brand experiences. Microsoft. Available at: http://mediaplant.net/Content/reports/From-Big-Data-to-Smart-Data.pdf (accessed: 22.02.2016).

Wren, G.P., Carlsson, S., Respicio, A., Brezillon, P. (2014) DSS 2.0 - Supporting Decision Making with New Technologies. IOS Press, Amsterdam, Netherlands.

Xiang, Z., Schwartz, Z., Gerdes, J.H., Uysal, M. (2014) What can big data and text analytics tell us about hotel guest experience and satisfaction? International Journal of Hospitality Management. Vol 44, pp: $120-130$.

York, J. (2015) The Marketing Management Process Defined. Markodojo's - The art of agile marketing. December, 2015. Available at: http://www.markodojo. $\mathrm{com} /$ marketing-management-process-defined/ (Accessed: 5.02.2016).

Živković, R., Njegus, A., Gajić, J., Brdar, J., Mijajlovic, I. (2015) Online Community Management in Hospitality. Proceedings of International Scientific Conference - SITCON 2015 "Competitiveness Factors of Tourism Enterprises”. Vol 1, pp: 133-139. 